Hunter, H. (1969). A controlled study of the psychopathology and physical measurements of Klinefelter's syndrome. British fournal of Psychiatry, 115, 443-448.

Maclean, N., Harnden, D. G., Court Brown, W. M., Bond, J., and Mantle, D. J. (1964). Sex chromosome abnormalities in newborn babies. Lancet, 1, 286-290.

Moorhead, P. S., Nowell, P. C., Mellman, W. J., Battips, D. M., and Hungerford, D. A. (1960). Chromosone preparations of leukocytes cultured from human peripheral blood. Experimental Cell Research, 20, 613-616.

Pitcher, D. R. (1971). The XYY syndrome. British fournal of Hospital Medicine, 5, 379-393.

Sumner, A. T., Robinson, J., A., and Evans, H. J. (1971). Distinguishing between $\mathrm{X}, \mathrm{Y}$ and $\mathrm{YY}$-bearing human spermatozoa by fluorescence and DNA content. Nature New Biology, 229, 231-233.

Townes, P, L., Ziegler, N., A. and Lenhard, L. W. (1965). A patient with 48 chromosomes (XYYY). Lancet, 1, 1041-1043.

\section{Deletion from the Long Arm of Chromosome 4 (46,XX,4q-) Associated with Congenital Anomalies*}

Summary. A congenitally malformed infant with a partial deletion of the long arm of chromosome 4 identified by Giemsa banding studies is described. The relationship of the anomalies to the chromosome abnormality is discussed.

Although a number of chromosome deletion syndromes involving the $B$ group have been described, only the cri-du-chat syndrome $(5 p-)$ and Wolf syndrome $(4 p-)$ have been reported often enough for an associated constellation of anomalies to be delineated (Guthrie et al, 1971; Hamerton, 1971). We wish to describe a congenitally malformed infant with a partial deletion of the long arm of chromosome 4 identified by Giemsa banding studies. Case reports involving a ring 4 chromosome have been published (Carter, Baker, and Hayman, 1969; Dallaire, 1969; Faed, Stewart, and Keay, 1969; Hecht, 1969; Surana, Bailey, and Conen, 1971) but only one previous report describes a deletion from only the long arm $(4 q-)$ (Ockey et al, 1967). Chromosome identification in these cases was by morphology or autoradiography.

\footnotetext{
Received 31 July 1972 .

* Requests for reprints to Mitchell S. Golbus, MD, Department of Pediatrics, University of California-San Francisco, California 94122, USA.
}

\section{Case Report}

K.R., a black female, is the first child of a 22 -year-old mother and 21-year-old father. She weighed $3360 \mathrm{~g}$ at birth and was born at term by a spontaneous vaginal delivery. There was no family history of congenital malformations or mental retardation, and the parents were not related. No drugs were ingested during the early part of pregnancy and there were no prenatal infections. However, the gestation was complicated by peripheral oedema in the eighth month treated with a two-week course of diuretics. The patient was referred to the University of California Medical Center at 4 weeks of age for failure to thrive, recurrent regurgitation, and tachypnoea without cyanosis while feeding.

Positive physical findings included a prominent occiput, superiorly pointed (elfin) ears with incomplete helices, a shortened nasal septum causing an upturned nose, a midline cleft of the palate, a bifid uvula, mild micrognathia, pour oropharyngeal muscular tone in contrast to good generalized tone, a grade III/VI harsh systolic murmur, an accentuated pulmonic second heart sound, an enlarged liver, a $1 \mathrm{~cm}$ umbilical hernia, a $1 \mathrm{~cm}$ café-au-lait spot in the right lower quadrant of the abdomen, a sacral dimple, a short distal phalanx of the left fifth finger with an absent extensor crease, and bilateral plantar displacement of the third toes (see Fig. 1).

Dermatoglyphics revealed seven ulnar loops, two whorls, and one radial loop with both palms having a single axial triradius (atd angle $=25^{\circ}$ ). A hallucal arch pattern was present bilaterally.

An intravenous pyelogram showed a duplicated left intrarenal collecting system. Cardiac catheterization with angiograms revealed pulmonary hypertension, an enlarged right atrium and ventricle, a small atrial septal defect (ASD) with left-to-right shunting, and inadequate alveolar ventilation. No cause for the last finding other than the relative macroglossia, increased pharyngeal secretions, and poor oropharynx muscle control was found. For the same reasons poor feeding was a continuing problem.

An endotracheal tube improved ventilation and at 6

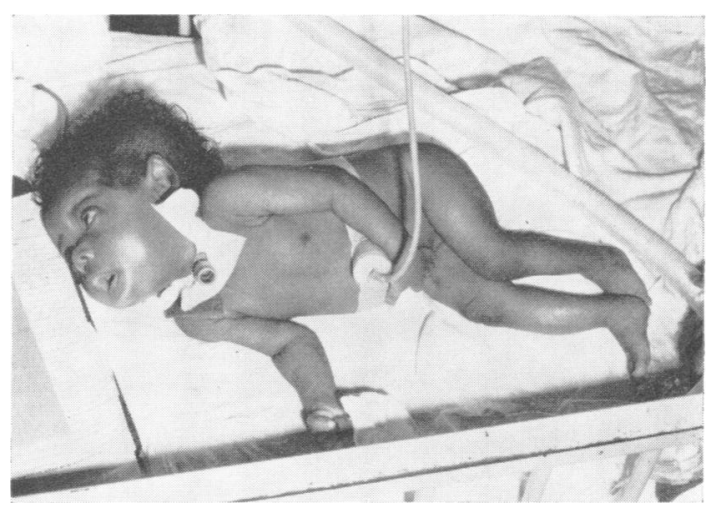

Fig. 1. The proposita at one month of age. 
weeks of age a tracheostomy and feeding gastrostomy were done. The intractability of the congestive heart failure to medical therapy led to the surgical correction of the $4 \times 8 \mathrm{~mm}$ ASD. Postoperatively she had a dramatic improvement including a marked and steady weight gain. The oxygen enrichment of her environment was progressively decreased until she was breathing room air but attempts to decrease the size of the tracheostomy tube were unsuccessful.

An electroencephalogram at 8 weeks of age was read as 'focal bioccipital disturbances, immature cerebral electrogenesis, and no epileptiform abnormalities'. A repeat study at 11 weeks of age showed maturation of cerebral electrogenesis and less focal occipital disturbances. Audiometry revealed grossly normal hearing. A developmental evaluation using the Bagley Scales of Infant Development indicated only a slight psychomotor delay in development compatible with the chronicity of her hospitalization.

At 4 months of age the patient was transferred to a chronic care unit for long term tracheostomy and gastrostomy care. By 6 months of age both surgical tubes were still in place, but she was starting to swallow well and take milk and baby food orally. She manifested a slow but steady weight gain. She smiled socially and played with toys and showed progressive development but at a slower than normal rate.

Analysis of cultured peripheral lymphocytes revealed 46 chromosomes with a deletion involving one of the $B$ group chromosomes. Giemsa banding studies (modified method of Sumner, Evans, and Buckland, 1971) delineated the karyotype as $46, \mathrm{XX}, 4 \mathrm{q}$ - with the deletion involving the terminal band (Fig. 2). Peripheral blood cultures from both parents produced normal karyotypes.
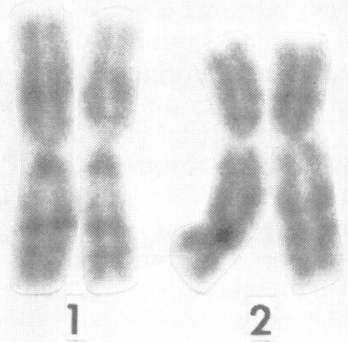

2

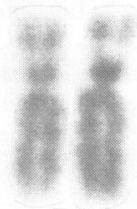

6

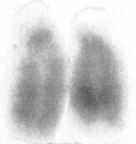

13
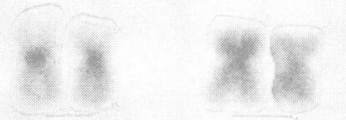

19

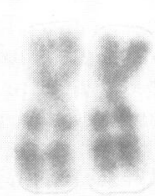

7

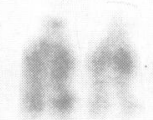

14

20
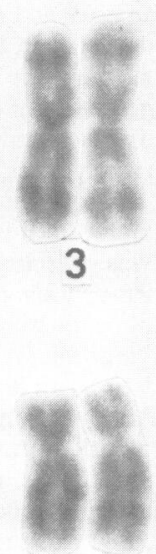

8

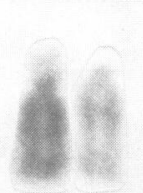

15

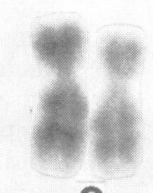

9

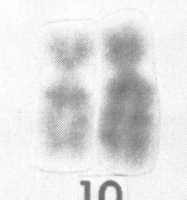

10

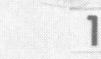

11

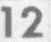

5
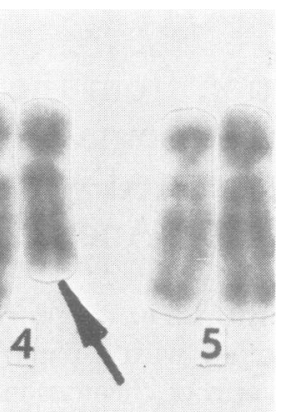

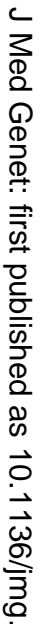

Fig. 2; Karyotype from peripheral blood with Giemsa banding. Note the deletion of the terminal band from the long arm of chromosome $4(4 q-)$. 


\section{Discussion}

A literature review disclosed only six patients with abnormalities associated with a deficiency of the long arm of chromosome 4, and five of these had a ring chromosome (Ockey et al, 1967; Carter et al, 1969; Dallaire, 1969; Faed et al, 1969; Hecht, 1969; Surana et al, 1971). The only anomalies common to three or more of these patients were low birth weight, radial anomalies, abnormally formed ears, cleft palate and/or hare lip, and cardiac structural defects. The patients with the ring 4 chromosome shared a number of features in common with those having the Wolf syndrome $(4 p-)$. This is not surprising since deletion of the short arm is presumably involved in forming the ring chromosome. Although the one other patient with a $4 \mathrm{q}-$ deletion had radial anomalies our patient did not. Until many more patients with the $4 \mathrm{q}$ - deletion are described it will be impossible to delineate a syndrome associated with the karyotype.

Chromosome polymorphisms have been noted to be more common in American Negroes than in the Caucasian population (Lubs and Ruddle, 1971). In their study of $\mathbf{4 4 8 2}$ newborns, polymorphism of the Denver A, C, D, E, and G groups were noted but none were found of the $B$ group chromosomes. The normal karyotype of both our patient's parents excludes a familial marker chromosome or balanced translocation state. This suggests the patient's chromosome deletion is significant and related to her anomalies.

This work was supported by grants from the National Foundation-March of Dimes; the Maternal and Children Health Services (USPHS) and the John A. Hartford Foundation.

Mitchell S. Golbus, Felix A. Conte, and DonNa L. DAENTL

\section{Department of Pediatrics, University of California-} San Francisco, San Francisco, California, USA

\section{REFERENCES}

Carter, R., Baker, E., and Hayman, D. (1969). Congenital malformations associated with a ring 4 chromosome. Fournal of Medical Genetics, 6, 224-227.

Dallaire, L. (1969). A ring B chromosome in a female with mutiple skeletal abnormalities. Birth Defects: Original Article Series, 5, pt. 5, pp. 114-116. National Foundation-March of Dimes, New York.

Faed, M., Stewart, A., and Keay, A. J. (1969). Chromosome abnormalities in two cases with bilateral radial element defects. fournal of Medical Genetics, 6, 342-346.

Guthrie, R. D., Aase, J. M., Asper, A. C., and Smith, D. W. (1971). The 4p- syndrome. American fournal of Diseases of Children, 122, $421-425$.
Hamerton, J. L. (1971). Human Cytogenetics: Clinical Cytogenetics. Vol. 2. Academic Press, New York.

Hecht, F. (1969). Ring-4-chromosome: ring autosomes, Lorelei of clinical-karyotype correlation and deletion mapping. Birth Defects: Original Article Series, 5, pt. 5, pp. 106-113. National Foundation-March of Dimes, New York.

Lubs, H. A. and Ruddle, F. H. (1971). Chromosome polymorphism in American Negro and White populations. Nature, 233, 134136.

Ockey, C. H., Feldman, G. V., Macaulay, M. E., and Delaney, M. J. (1967). A large deletion of the long arm of chromosome no. 4 in a child with limb abnormalities. Archives of Disease in Childhood, 42, 428-434.

Sumner, A. T., Evans, H. J., and Buckland, R. A. (1971). New technique for distinguishing between human chromosomes. Nature New Biology, 232, 31-32.

Surana, R. B., Bailey, J. D., and Conen, P. E. (1971). A ring-4 chromosome in a patient with normal intelligence and short stature. Fournal of Medical Genetics, 8, 517-521.

\section{Monozygotic Twins with Ring Chromosome 22}

Summary. Mentally retarded and monozygous twin sisters, with little physical abnormality, are described. Each twin carried a small ring chromosome, identified as a number 22 .

\section{Case Report}

The twins (J.G. and C.G.) were first seen by us at $4 \frac{3}{4}$ years. They had always been considered 'identical'. They were the last-born in a sibship of five, and their mother had also miscarried an apparently normal female at 6-months' gestation. She was aged 24 when the twins were born. Both parents and all sibs were physically healthy and intellectually normal.

The twins presented as breeches after an uneventful pregnancy, and were delivered at term; birth weights were $2300 \mathrm{~g}$ and $2350 \mathrm{~g}$. The neonatal period was uneventful and their early development normal; they were said to have smiled at 6 weeks, sat unsupported at 7 months, walked alone at 13 months, and spoken two words by 17 months. Retarded intellectual development was noted in the second year of life, and increased in severity, so that at $4 \frac{3}{4}$ years they scored a social age below 2 years (Vineland scale), and had a DQ of 35-40 on the Merrill-Palmer test.

Other clinical data are recorded in Table I. Compared with their sibs, they showed reduced stature and head circumference, but their weights were normal. Fig. 1 shows their facial similarity; at $4 \frac{3}{4}$ years both their noses had a depressed bridge and a bulbous tip, but a year later (when Fig. 1 was taken) they had assumed a

Received 15 September 1972. 